\title{
Assessing the Validity of a Physical Activity Questionnaire Developed for Parents of Preschool Children in Mexico
}

\author{
Montserrat Bacardi-Gascón', Claudia Reveles-Rojas', Gail Woodward-Lopez², \\ Patricia Crawford ${ }^{2}$, Arturo Jiménez-Cruz' \\ ' Facultad de Medicina y Psicología, Universidad Autónoma de Baja California, México, Unidad Universitaria, Avda, \\ Universidad I44I8, Parque Industrial Internacional, 22390 Tijuana, B.C., Mexico; ${ }^{2}$ Center for Weight and Health, \\ University of California-Berkeley, 3 Giannini Hall, Berkeley, CA 94720, USA
}

\begin{abstract}
To assess the validity of a questionnaire developed for parents of preschool children to know their physical activity (PA) status, we compared the questionnaire results with the measures of accelerometer for children's activities. Thirty-five preschoolers who wore the accelerometer for at least 10 hours daily on 3 weekdays and one weekend day were included in the analyses. Time spent in activities of varied intensity was calculated by applying 15-second ActiGraph count cutoffs (ACC). Parents' perceptions of their children's PA were associated with the percentage of vigorous and moderate physical activity recorded with ACC at $\mathrm{r}=0.62(\mathrm{p}=0.0001)$. An association was shown between the percentage of a child's time spent in vigorous physical activity, as reported by parents, with that measured by ACC at $\mathrm{r}=0.53$ ( $\mathrm{p}=0.001$ ). Results of this study suggest that the designed questionnaire might be a useful tool for assessing children's activity while, additionally, it warrants further investigation on larger samples of children.
\end{abstract}

Key words: Accelerometer; Physical activity; Preschool children; Validity assessment; Mexico

\section{INTRODUCTION}

The reported prevalence of overweight and obesity among five-year old children in Mexico is $17.7 \%$ (1), and among 3-5 year old children in poor, rural Mexico, the rate is greater than 23\% (2). The preschool years are identified as a period of risk for the development of obesity that may last up to adulthood $(3,4)$. Several authors have pointed out that decreased physical activity (PA) or high levels of sedentary behaviour are contributing to an increase in childhood overweight $(5,6,7,8)$, and that preschoolers do not meet PA recommendations $(9,10)$.

To obtain survey data on young children's PA, it is necessary to rely on reports from parents or adult caregivers since young children are unable to accu-

Correspondence and reprint requests:

Dr. Arturo Jiménez-Cruz

Unidad Universitaria

Avda, Universidad 14418

Parque Industrial Internacional

22390 Tijuana, B.C.

Mexico

Email: ajimenez@uabc.edu.mx OR

arturojimenezc@yahoo.com rately self-report their physical activities (11). Sets of questionnaire administered to caregivers to assess young children's usual or actual PA have added benefits: these are inexpensive, non-invasive, and less time-consuming to administer and interpret (12). Given these benefits, careful evaluation of the validity of reports based on questionnaire is merited (13).

Accelerometer is considered to be a reliable instrument for the measurement of PA in preschool children and, therefore, are used for validation of other measures, including questionnaire $(14,15,16,17)$. Further, sedentary behaviour can be quantified using accelerometry in preschool children (18). Since children engage in very short bursts of intense PA, along with varying intervals of low and moderate intensity $(19,11,20)$, the use of the accelerometer set at 15 seconds (15-s) increment is recommended. Several studies have used accelerometers to evaluate the validity of different types of questionnaire used for parents to assess preschoolers' PA $(21,22,23,24)$. Harro used a daily registry of activities during working-days (21); Chen et al. assessed the frequencies and preferences of $\mathrm{PA}$, using a questionnaire for teachers (22); Burdette et al. used a checklist to assess outdoor playing (23); and Janz et al. assessed 
preferences and choices of everyday activity (24). The ActiGraph uniaxial accelerometer has been evaluated and calibrated using 15-s data-collection increment with direct observation (15) and using a metabolic criterion measure (VO2) (25) for 3-5 year old children. However, we have found no simple tools to assess usual PA among preschool children. Little is known about the PA behaviour of preschool children in Mexico, and no questionnaire has been developed and validated for assessment of PA in Mexican preschool children. Parental perception of children's PA and the degree of understanding of the questionnaire might be determined by cultural patterns; therefore, translating a questionnaire developed for parents with different levels of education might yield inaccurate results. Designing of the culturally-appropriate questionnaire is warranted. Besides, due to the high percentage of the Mexican population with low reading and comprehension levels, a simpler tool for assessing usual PA needs to be evaluated. Thus, the aim of this study was to assess the validity of a physical activity questionnaire developed for use by parents of Mexican preschool children.

\section{MATERIALS AND METHODS}

\section{Participants}

Forty-five 3-5 year old children enrolled in 3 classes in a preschool care centre in Tijuana, Mexico and their parents were recruited to participate in this cross-sectional study. Children attended the preschool care centre four hours daily, from 9:00 am to $1: 00 \mathrm{pm}$, Monday through Friday. The study protocol and procedures for obtaining the children's assent and informed consent of their parents were reviewed and approved by the Committee for the Protection of Human Subjects, University of California at Berkeley and the Committee for the Protection of Human Subjects, Medical School of Universidad Autónoma de Baja California (26).

\section{Settings}

Tijuana city is at the extreme northwestern part of Mexico, and it borders the state of California, USA. In 2006, Tijuana had approximately 1,795,000 residents, and approximately $9 \%$ of the population was younger than 5 years. Government's projections indicate that $77 \%$ of preschool children were enrolled at care centres (27).

\section{Anthropometric measurements}

Height was measured to the nearest millimetre, with a portable stadiometer (model 214 Seca Corp., Hanover, MD, USA), and weight was measured with electronic scales (model Tanita UM-028, Tokyo, Ja- pan) to the nearest $0.1 \mathrm{~kg}$. Body mass index (BMI) was calculated in $\mathrm{kg} / \mathrm{m}^{2}$. BMI values were compared with age/gender BMI percentiles from the Centers for Disease Control and Prevention Growth Charts (28).

\section{Accelerometer data}

PA data on 45 children were quantified based on ActiGraph GT1M accelerometer (ActiGraph, Fort Walton Beach, FL) data collected during weekdays (home and preschool centre) and weekends (home) between October 2006 and March 2007. Only 35 participants (3-5 years of age) (51\% girls) who wore the accelerometer on the right hip for at least 10 hours daily on 3 weekdays and one weekend day were included in the analyses. Ten children who did not meet the adequate daily hours on 3 weekdays and one weekend as recommended were excluded. The ActiGraph was programmed to record activity counts in 15-second intervals to detect time spent in spontaneous activities. Children wore the accelerometers on the right hip, secured with an elastic belt. Parents and preschool teachers were instructed by a researcher on how to place and monitor the ActiGraph correctly during the day (CR). Parents placed the accelerometers on their children each morning and removed those at night prior to bedtime. Activity counts for each 15 -s interval were obtained from the Actilife GTM1 software (version 2.1.9) developed to process the data from the ActiGraph GTM1. Time spent in PA of different intensities at preschool centre and at home was calculated by applying two different 15-s ActiGraph count cutoffs (ACC) that represent two different methods of deriving cutoff points as follows:

a. The age-specific cutoff typology developed by Sirard et al. based on age-dependent ROC curves of the age-specific counts/15-s cutoffs for 3, 4, and 5 years for the activities of different intensities (15): sedentary (0-301), (0-363), and (0-398); light (302-614), (364-811), and (399-890); moderate (615-1230), (812-1234), and (891-1254); and vigorous $(\geq 1231),(\geq 1235)$, and $(\geq 1255)$. The ACC for PA of moderate and vigorous intensity were set at $\geq 615, \geq 812$, and $\geq 891$ counts/15-s.

b. The cutoff typology developed by Pate et al. was based on measuring $\mathrm{VO}_{2}$ while children performed unstructured PA (25). The ACC for PA of moderate and vigorous intensity was set at 420 counts $/ 15-\mathrm{s}\left(\mathrm{VO}_{2}=20 \mathrm{~mL} / \mathrm{kg}\right)$ and 842 counts $/ 15-\mathrm{s}$ $\left(\mathrm{VO}_{2}=30 \mathrm{~mL} / \mathrm{kg}\right)$ respectively.

Two different data files were made-one with data collected during school hours and another including data collected during weekdays and weekends. 


\section{Questionnaire}

A six-item questionnaire was developed for and completed by parents (Appendix A) on the days when the children wore the accelerometers. The questionnaire was piloted for comprehension and reproducibility. Twenty-one parents participated in the pilot study. The questionnaire was selfadministered, and the research assistant clarified any questions about its application. Six questions asked parents to report the usual amount of time per day spent in sleeping, naps, and various indoor and outdoor activities, which were grouped according to PA intensity (sedentary, moderate, and vigorous). From the information provided by parents through the questionnaire, the amount of daily time spent in different intensities of PA was computed in minutes and as a percentage of time at home and preschool centre. Sports and supervised activities were recorded weekly and computed to minutes/day of different PA levels according to the reported activity.

One additional question (Appendix) was asked to assess parents' overall perception of the child's typical PA level by assigning it to one of the three categories ranging from 1 (inactive) to 3 (very active).

To assess the test-retest reliability, the questionnaire was re-administered to 21 mothers after one week; the correlations between test and retest for duration of low, moderate, and vigorous activities were $0.86(\mathrm{p}=0.01), 0.79(\mathrm{p}=0.04)$, and $0.94(\mathrm{p}=0.002)$ respectively. For the general question on overall activity, the level was $0.97(\mathrm{p}=0.001)$.

\section{Statistical analysis}

To compare total counts in boys and girls, between weekdays and weekends, the Mann-Whitney test was used. To estimate the degree of association between different days of measurements, the intraclass correlation coeficient (ICC) was calculated. Spearman correlation was used in evaluating the different ACC used. To evaluate the validity of the questionnaire, Spearman correlations were used for comparing percentages of different intensities of PA assessed from the questionnaire with the percentages of PA obtained from accelerometer cutoff points. To evaluate differences between minutes per hour spent in different intensities of PA, with the responses to the qualitative question by mothers, the Kruskal Wallis Test was performed. All tests were conducted with a two-tailed alpha level of 0.05. Analyses were performed using the SPSS for Windows (version 16.0).

\section{RESULTS}

The mean age of the 35 children (51\% girls) was $4.4 \pm 0.7$ years (range 3-5 years), and the mean BMI was $15.8 \pm 2.7 \mathrm{~kg} / \mathrm{m}^{2}$ (range $10.8-21.7$ ). The average BMI was at the $65^{\text {th }}$ percentile for age and gender; $23 \%$ were either overweight or obese $\left(\mathrm{BMI} \geq 85^{\text {th }}\right.$ percentile for age and gender). Mean sleeping time was $9.8 \pm 1.1 \mathrm{~h} /$ day, and $33 \%$ of the children reported daily naps $(0.7 \pm 1.2 \mathrm{~h} /$ day $)$. The recorded mean time of accelerometer-use was $11 \pm 1.7 \mathrm{~h} / \mathrm{d}$ for an average of $3.8 \pm 0.9$ weekdays and $1.6 \pm 0.5$ weekend days. ICC calculating the degree of association between different days of measurements was $0.76,0.77$, and 0.74 for school, weekdays, and weekends.

Total daily mean counts/15-s measured by accelerometer were $178 \pm 75$ : for weekdays $185 \pm 83$, for weekends $152 \pm 65$, and for the time spent at preschool centre $221 \pm 105$.

The correlations between parents' answers to the broad question assessing children's typical activity level and children's percentage of time spent in moderate $(\mathrm{M})$, vigorous $(\mathrm{V})$, and moderate+vigorous activity (MV) with ACC (using method of Sirard et al.) were $\mathrm{r}=0.57(\mathrm{p}=0.0001)$ and $\mathrm{r}=0.62(\mathrm{p}=0.0001)$ respectively (Table 1$)$. Percentages of time spent in $\mathrm{V}$ and $\mathrm{MV}$ reported by parents on the questionnaire were significantly correlated with time spent in $\mathrm{V}$ from Sirard et al. [ACC $\mathrm{r}=0.53(\mathrm{p}=0.001)]$ and Pate et al. [ACC $\mathrm{r}=0.41(\mathrm{p}=0.01)]$ (Table 1$)$. There were statistically significant differences between means in time spent in each PA intensity category (min/h) by ACC (Sirard et al.) and parents' answers to the broad question about perception of their children's overall PA level (Table 2).

Table 3 shows the percentage of time spent in different PA intensities according to questionnaire responses and ActiGraph count cutoffs. It shows higher percentages of moderate to vigorous PA when using the Pate cutoff points. Additionally, similar percentages of sedentary PA at home were reported using the parents' questionnaire and ACC cutoff points. Using the questionnaire, we observed differences between the percentage of PA at home and at school and the percentage of time spent in sedentary PA. No difference was found, using the Pate and Sirard cutoff points. Furthermore, parents overestimate time spent in vigorous PA (Table 3). 


\begin{tabular}{|c|c|c|c|c|c|c|c|c|c|}
\hline \multicolumn{4}{|l|}{$\begin{array}{l}\text { Parents' } \\
\text { questionnaire }\end{array}$} & \multicolumn{6}{|c|}{ Accelerometer data (ACC) } \\
\hline \multirow[b]{2}{*}{ Physical activity } & & \multicolumn{4}{|c|}{ ACC Sirard et al. 2005} & \multicolumn{4}{|c|}{ Pate et al. 2006} \\
\hline & & $S$ & $\mathrm{M}$ & $\mathrm{V}$ & MV & $S$ & $\mathrm{M}$ & $\mathrm{V}$ & MV \\
\hline Sedentary (S) & Rho & $0.35^{*}$ & 0.11 & $-0.40^{*}$ & $-0.50^{\star \star}$ & $0.34^{*}$ & 0.05 & $-0.37^{*}$ & $-0.34^{*}$ \\
\hline Moderate (M) & Rho & -0.31 & -0.23 & $0.40^{*}$ & -0.13 & -0.27 & -0.07 & $0.34^{*}$ & -0.04 \\
\hline Vigorous (V) & Rho & $-0.62 \ddagger$ & $0.40^{*}$ & $0.53 \dagger$ & $0.54 \dagger$ & $-0.45^{\star *}$ & -0.02 & $0.41^{* *}$ & $0.37^{*}$ \\
\hline $\mathrm{M}+\mathrm{V}(\mathrm{MV})$ & Rho & $-0.34^{*}$ & 0.31 & $0.61 \ddagger$ & $0.49^{\star *}$ & -0.13 & 0.03 & $0.43^{* *}$ & $0.34^{*}$ \\
\hline $\begin{array}{l}\text { Perceptions of } \\
\text { child's activity }\end{array}$ & Rho & $-0.45^{* *}$ & $0.57^{\dagger}$ & $0.50^{\star *}$ & $0.62 \ddagger$ & $-0.35^{*}$ & 0.25 & $0.47^{* *}$ & $0.35^{*}$ \\
\hline
\end{tabular}

Table 2. Median differences in physical activity measured by ACC according to parents' perception of children's PA

\begin{tabular}{|c|c|c|c|c|}
\hline & \multicolumn{4}{|c|}{ Median physical activity [min/h1 $($ mean \pm SD)] } \\
\hline & Sedentary (S) & Light (L) & Moderate (M) & Vigorous (V) \\
\hline \multicolumn{5}{|l|}{ Perceptions of child's activity ${ }^{2}$} \\
\hline Low & $\begin{array}{c}51.6 \\
(52.5 \pm 3.0)\end{array}$ & $\begin{array}{c}6.8 \\
(6.1 \pm 2.5)\end{array}$ & $\begin{array}{c}1.1 \\
(0.9 \pm 0.5)\end{array}$ & $\begin{array}{c}0.4 \\
(0.4 \pm 0.2)\end{array}$ \\
\hline Moderate & $\begin{array}{c}51.6 \\
(52.0 \pm 2.4)\end{array}$ & $\begin{array}{c}6.1 \\
(6.0 \pm 1.8)\end{array}$ & $\begin{array}{c}1.5 \\
(1.4 \pm 0.7)\end{array}$ & $\begin{array}{c}0.7 \\
(0.7 \pm 0.5)\end{array}$ \\
\hline Vigorous & $\begin{array}{c}48.0 \\
(48.0 \pm 1.7)\end{array}$ & $\begin{array}{c}7.9 \\
(8.4 \pm 1.4)\end{array}$ & $\begin{array}{c}2.5 \\
(2.6 \pm 0.9)\end{array}$ & $\begin{array}{c}0.9 \\
(1.1 \pm 0.4)\end{array}$ \\
\hline $\mathrm{p}$ values 3 & 0.007 & 0.02 & 0.004 & 0.017 \\
\hline Total & $\begin{array}{c}50.7 \\
(51.3 \pm 2.9)\end{array}$ & $\begin{array}{c}6.8 \\
(6.4 \pm 2.0)\end{array}$ & $\begin{array}{c}1.5 \\
(1.5 \pm 0.9)\end{array}$ & $\begin{array}{c}0.7 \\
(0.7 \pm 0.5)\end{array}$ \\
\hline \multicolumn{5}{|c|}{$\begin{array}{l}\text { Low: normally sits down while playing, watching TV, colouring or playing with dolls or stuffed animals } \\
\text { and singing. Moderate: combines playing while sitting down and standing up with activities that in- } \\
\text { clude walking from one side of the room or house to the other. Vigorous: does not stop moving, goes } \\
\text { from one side of the house to the other, goes up and down the stairs, runs and jumps; }{ }^{1} \text { ActiGraph count } \\
\text { cutoffs, Sirard et al., } 2005{ }^{2} \text { By parents at home; }{ }^{3} \text { Kruskal Wallis Test; SD=Standard deviation }\end{array}$} \\
\hline
\end{tabular}

\begin{tabular}{|c|c|c|c|c|c|c|c|c|}
\hline \multirow{2}{*}{$\begin{array}{l}\text { Reading } \\
\text { source }\end{array}$} & \multicolumn{2}{|c|}{$\begin{array}{l}\% \text { of time in } \\
\text { sedentary PA }\end{array}$} & \multicolumn{2}{|c|}{$\begin{array}{l}\% \text { of time in } \\
\text { light PA }\end{array}$} & \multicolumn{2}{|c|}{$\begin{array}{l}\% \text { of time in } \\
\text { moderate PA }\end{array}$} & \multicolumn{2}{|c|}{$\begin{array}{l}\% \text { of time in } \\
\text { vigorous PA }\end{array}$} \\
\hline & Home & $\begin{array}{c}\text { Pre- } \\
\text { school } \\
\text { centre }\end{array}$ & Home & $\begin{array}{c}\text { Pre- } \\
\text { school } \\
\text { centre }\end{array}$ & Home & $\begin{array}{c}\text { Pre- } \\
\text { school } \\
\text { centre }\end{array}$ & Home & $\begin{array}{c}\text { Pre- } \\
\text { school } \\
\text { centre }\end{array}$ \\
\hline $\begin{array}{l}\text { Parent's } \\
\text { question- } \\
\text { naire }\end{array}$ & $83.0 \pm 8.9$ & - & - & - & $6.0 \pm 4.7$ & - & $11 \pm 7.2$ & - \\
\hline $\begin{array}{l}\text { Pate et al. } \\
2006\end{array}$ & $87.4 \pm 4.2$ & $85.1 \pm 5.6$ & - & - & $9.0 \pm 2.9$ & $10.6 \pm 4.0$ & $3.5 \pm 1.6$ & $4.3 \pm 2.0$ \\
\hline $\begin{array}{l}\text { Sirard et al. } \\
2005\end{array}$ & $85.6 \pm 4.8$ & $82.9 \pm 5.9$ & $10.7 \pm 3.4$ & $12.4 \pm 4.3$ & $2.6 \pm 1.5$ & $3.1 \pm 1.9$ & $1.2 \pm 0.8$ & $1.5 \pm 1.2$ \\
\hline
\end{tabular}




\section{DISCUSSION}

This study shows that responses to the questionnaire on parents' perceptions of their children's physical activity were moderately associated with the moderate and vigorous PA recorded with ACC. In addition, children who were shown by ACC to spend more minutes per hour on light, moderate and vigorous PA and less time in sedentary activities were more likely to be perceived by their parents as active (Table 2). This result indicates that the parents' responses to the questionnaire provide a good estimate of preschool children's PA in this sample of children living in the northwestern region of Mexico. Other studies have shown similar results. Janz et al. reported an association between the responses to parents' questionnaire on children's behavioural traits and vigorous PA. They also showed that children with the highest parental questionnaire scores were 2.7 times more likely to be in the highest percentile for total activity as measured by an accelerometer than those with low or moderate parental questionnaire scores (24).

In the present study, an association was found between the reported percentage of time spent in vigorous PA and moderate and vigorous PA from parents' responses to the questionnaire and the results of ACC (using Sirard et al.). Likewise, Harro found a correlation in kindergarten and elementary school children between the duration of moderate and vigorous PA reported by the parents' questionnaire and the Caltrac accelerometer (21).

In this study, we found that associations were higher, using the ACC by Sirard et al. (15) than when the Pate et al.'s ACC was used (25). Therefore, depending on the method used, the validation of a questionnaire or the assessment of the PA can yield different results. There is currently enormous variation in the practice between researchers and the use of cutoff points. In a recent review conducted by Reilly et al., it was suggested that the biological plausibility should be considered, along with the quality of the evidence and the mass and consistency of the evidence to identify the best cuttoff points (29). Though based on different methods of deriving cutoff points, we have seen consistent results among 3-5 year old children, using cutoff points from Sirard et al. and Pate et al.

The children in this study were engaged (depending on the ACC used) from 2.8 to $8.8 \mathrm{~min} / \mathrm{h}$ of moderate and vigorous PA at preschool centre $(4.5-15 \%$ of the 4 hours recorded). This relatively low level of PA in the preschool children is consistent with the results observed in other studies conducted in different preschool settings $(17,30)$. Pate et al. reported moderate and vigorous PA of $7.7 \mathrm{~min} / \mathrm{h}(\sim 13 \%$ of the time registered) (17). However, they found important differences among the preschool settings. Finn et al. also reported variation (30) in the time spent in vigorous PA depending on the centre that the children attended (3.6-6.0\%). We did not assess differences between preschool settings.

During PA at home, $4-12 \%$ of time was spent in moderate and vigorous $\mathrm{PA}$, slightly less than that measured in the preschool setting. The highest percentages of moderate and vigorous PA (Table 3) were recorded when using ACC by Pate et al. (25). As reported in other studies $(31,32,33)$, the preschool children whom we studied did very little moderate and vigorous PA at home and were sedentary most of the time.

Our study also indicates that children at home and preschool centre, during weekdays and weekends, spend $80 \%$ of their time in sedentary behaviours (Table 3), which is less than the reported $90 \%$ as measured, using the same accelerometer methodology among Latino preschool children in Redwood City, California (9). The average BMI of participants in the California study was also higher (at the $85^{\text {th }}$ percentile for age and gender) than in Baja California (at the $65^{\text {th }}$ percentile for age and gender).

The questionnaire might be a simple and useful tool to assess the PA of preschool children at the Mexican daycare facilities, and the information collected might also be used for sending an alert for medical referrals, which will aid physicians in making a definite diagnosis and prescribing adequate treatment. Additionally, if validated in different settings, it could be used in promoting and evaluating preventive and intervention programmes.

Strength of the present study is the use of accelerometers to validate children's physical activity objectively. This study used the cutoff points reported by Sirad et al. (15), which were validated with direct observation. Additionally, cutoff points proposed by Pate et al. (25), using a metabolic criterion measure $\left(\mathrm{VO}_{2}\right)$ for 3-5 years old children, were used. Therefore, the results of this study were evaluated using two different validated standards. This is the first study which validates the perceptions of Mexican parents about PA of their preschool children.

\section{Limitations}

One of the limitations of our study is the use of uniaxial accelerometers. Uniaxial accelerometers worn 
at the waist do not measure upper-body activities or activities occurring in a horizontal plane (15). This might be relevant since movement patterns in young children might have higher horizontal motion than older children. Activities of 15 or more minutes were recorded in the questionnaire, and shorter activity periods were not reported. Activity patterns were tested at only one point in the year, which does not allow for quantifying seasonal variation, and only 10 hours of observation per day were recorded. Thus, children might have been more active or more sedentary than the results of the study indicate.

Additionally, this study was conducted using a convenient sample in one preschool centre in a city located in the northwestern part of Mexico; thus, we could not assess differences between children from different settings, or children with or without siblings. Results of this study may not be generalized to other settings, regions, cultural populations or socioeconomic groups within Mexico.

\section{Conclusions}

Although parents' assessments of their children's PA, as measured by the questionnaire, cannot be used to provide point estimates of their children's overall PA, these assessments were significantly correlated to accelerometers reading, a direct measure of physical activity. The questionnaire in this study might be a simple and useful tool to assess the PA of preschool children at Mexican daycare facilities. However, further investigation is warranted to assess if the results are applicable in other daycare settings.

\section{REFERENCES}

1. Olaiz-Fernández G, Rivera-Dommarco J, ShamahLevy T, Rojas R, Villalpando-Hernández S, Hernández-Avila $\mathrm{M}$ et al. Encuesta nacional de salud y nutrición 2006. Cuernavaca: Instituto Nacional de Salud Pública, 2006. 131 p.

2. Fernald LC, Neufeld LM. Overweight with concurrent stunting in very young children from rural Mexico: prevalence and associated factors. Eur J Clin Nutr 2007;61:623-32.

3. Dietz WH. Periods of risk in childhood for the development of adult obesity-what do we need to learn? J Nutr 1997;127:1884S-6S.

4. Whitaker RC, Pepe MS, Wright JA, Seidel KD, Dietz WH. Early adiposity rebound and the risk of adult obesity. Pediatrics 1998;101:E5.

5. Gortmaker SL, Must A, Sobol AM, Peterson K, Colditz GA, Dietz WH. Television viewing as a cause of in- creasing obesity among children in the United States, 1986-1990. Arch Pediatr Adolesc Med 1996;150:356-62.

6. Tremblay MS, Willms JD. Is the Canadian childhood obesity epidemic related to physical inactivity? Int J Obes Relat Metab Disord 2003;27:1100-5.

7. Reilly JJ, Armstrong J, Dorosty AR, Emmett PM, Ness A, Rogers I et al.; Avon Longitudinal Study of Parents and Children Study Team. Early life risk factors for obesity in childhood: cohort study. BMJ 2005;330:1357-9.

8. Janz KF, Burns TL, Levy SM; Iowa Bone Development Study. Tracking of activity and sedentary behaviors in childhood: the Iowa Bone Development Study. Am J Prev Med 2005;29:171-8.

9. Alhassan S, Sirard JR, Robinson TN. The effects of increasing outdoor play time on physical activity in Latino preschool children. Int J Pediatr Obes 2007;2:153-8.

10. Reilly JJ. Physical activity, sedentary behaviour and energy balance in the preschool child: opportunities for early obesity prevention. Proc Nutr Soc 2008;67:317-25.

11. Welk GJ, Corbin CB, Dale D. Measurement issues in the assessment of physical activity in children. Res $Q$ Exerc Sport 2000;71(Suppl 2):S59-73.

12. Oliver M, Schofield GM, Kolt GS. Physical activity in preschoolers: understanding prevalence and measurement issues. Sports Med 2007;37:1045-70.

13. Fulton JE, Burgeson CR, Perry GR, Sherry B, Galuska DA, Alexander MP et al. Assessment of physical activity and sedentary behavior in preschool-age children: priorities for research. Pediatr Exerc Sci 2001;13:113-26.

14. Sirard JR, Pate RR. Physical activity assessment in children and adolescents. Sports Med 2001;31:439-54.

15. Sirard JR, Trost SG, Pfeiffer KA, Dowda M, Pate RR. Calibration and evaluation of an objective measure of physical activity in preschool children. J Phys Act Health 2005;2:345-7.

16. Kelly L, Reilly JJ, Fairweather SC, Barrie S, Grant S, Paton JY. Comparison of two accelerometers for assessment of physical activity in preschool children. Pediatr Exerc Sci 2004;16:324-33.

17. Pate RR, Pfeiffer KA, Trost SG, Ziegler P, Dowda M. Physical activity among children attending preschools. Pediatrics 2004;114:1258-63.

18. Reilly JJ, Coyle J, Kelly L, Burke G, Grant S, Paton JY. An objective method for measurement of sedentary behavior in 3- to 4-year olds. Obes Res 2003;11:1155-8.

19. Bailey RC, Olson J, Pepper SL, Porszasz J, Barstow TJ, Cooper DM. The level and tempo of children's physical activities: an observational study. Med Sci Sports Exerc 1995;27:1033-41. 
20. Nilsson A, Ekelund U, Yngve A, Sjöström M. Assessing physical activity among children with accelerometers using different time sampling intervals and placements. Pediatr Exerc Sci 2002;14:87-96.

21. Harro M. Validation of a questionnaire to assess physical activity of children ages 4-8 years. Res $Q E x$ erc Sport 1997;68:259-268.

22. Chen X, Sekine M, Hamanishi S, Wang H, Hayashikawa Y, Yamagami T et al. The validity of nursery teachers' report on the physical activity of young children. J Epidemiol 2002;12:367-74.

23. Burdette HL, Whitaker RC, Daniels SR. Parental report of outdoor playtime as a measure of physical activity in preschool-aged children. Arch Pediatr Adolesc Med 2004;158:353-7.

24. Janz KF, Broffitt B, Levy SM. Validation evidence for the Netherlands physical activity questionnaire for young children: the Iowa bone development study. Res Q Exerc Sport 2005;76:363-9.

25. Pate RR, Almeida MJ, McIver KL, Pfeiffer KA, Dowda M. Validation and calibration of an accelerometer in preschool children. Obesity (Silver Spring) 2006;14:2000-6.

26. Bacardí-Gascón M, Reveles-Rojas C, López Gail W, Crawford P, Jiménez-Cruz A. Validity of a physical activity questionnaire used with parents of preschool children in Mexico. Nutr Hosp 2011;26:244-5.
27. Instituto Nacional de Estadística y Geografía. II Conteo de Población y vivienda 2005. Aguascalientes: Instituto Nacional de Estadística y Geografía, 2009. 2 p. (http://www.inegi.org.mx, accessed on 17 May 2009).

28. Kuczmarski RJ, Ogden CL, Guo SS, Grummer-Strawn LM, Flegal KM, Mei Z et al. 2000 CDC Growth Charts for the United States: methods and development. $\mathrm{Vi}$ tal Health Stat 11 2002;(246):1-190.

29. Reilly JJ, Penpraze V, Hislop J, Davies G, Grant S, Paton JY. Objective measurement of physical activity and sedentary behaviour: review with new data. Arch Dis Child 2008;93:614-9.

30. Finn KJ, Specker B. Comparison of Actiwatch activity monitor and Children's Activity Rating Scale in children. Med Sci Sports Exerc 2000;32:1794-7.

31. Fisher A, Reilly JJ, Kelly LA, Montgomery C, Williamson A, Paton JY et al. Fundamental movement skills and habitual physical activity in young children. Med Sci Sports Exerc 2005;37:684-8.

32. Metallinos-Katsaras ES, Freedson PS, Fulton JE, Sherry B. The association between an objective measure of physical activity and weight status in preschoolers. Obesity (Silver Spring) 2007;15:686-94.

33. Reilly JJ, Jackson DM, Montgomery C, Kelly LA, Slater C, Grant S et al. Total energy expenditure and physical activity in young Scottish children: mixed longitudinal study. Lancet 2004;363:211-2. 
Appendix. Physical activity questionnaire for parents (translated from Spanish)

Card number Boy ( ) Girl ( )

1. How much time per day does your child spend doing the following activities?

Sitting down watching television. Sitting down playing (video games, toy cars or dolls, puzzles, colouring). Lying down in bed or an armchair.

15 min. () 30 min. () 45 min. () 1 hour ( ) more than 1 hour (how many hours? _ )

2. How much time per day does your child spend doing the following activities?

Walking to school. Walking to the park and in the park or on the patio. Walking in a mall or going to the convenient store (tiendita)

15 min. () 30 min. () 45 min. () 1 hour ( ) more than 1 hour (how many hours?__ )

3. How much time per day does your child spend doing the following activities?

Playing circle games. Playing ball. Playing and running. Playing on a bicycle or tricycle.

Play-fighting

15 min. () 30 min. () 45 min. () 1 hour ( ) more than 1 hour (how many hours?__ )

4. Does your child do any of these activities during the week?

Karate, Gymnastics, Football, Ballet or jazz, Baseball, Swimming. day(s) per week _ _ hour(s) per day

5. How many hours does your child sleep at night? hours

6. How many times a day does your child take a nap and for how long? time(s) a day

15 min. () 30 min. ( ) 45 min. () 1 hour ( ) more than 1 hour (how many hours?_ )

7. Which of these phrases best describes your child's activity at home?

a. () Normally sits down while playing, watching TV, colouring or playing with dolls or stuffed animals

b. () Combines playing while sitting down and standing up with activities that include walking from one side of the room or house to the other.

c. ( ) Does not stop moving, goes from one side of the house to the other, goes up and down stairs, runs and jumps. 